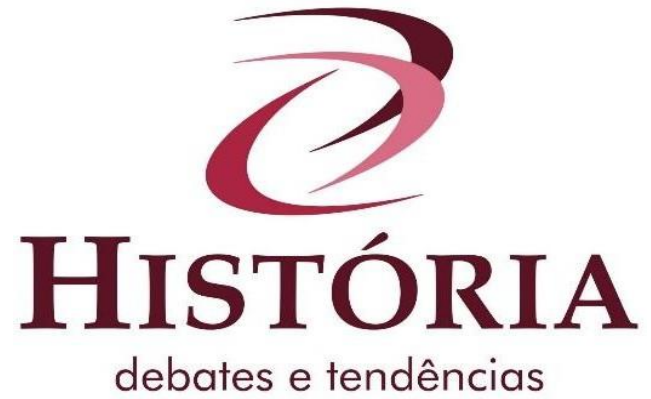

\title{
Notas sobre o estudo dos intelectuais: as contribuições teóricas de Bourdieu para o estudo de trajetórias intelectuais de agentes e instituições
}

\section{Notes on the study of intellectuals: the Bourdieu's theoretical contributions to the study of intellectual trajectories of agents and institutions}

\author{
Notas sobre el estudio de los intelectuales: las contribuciones teóricas de \\ Bourdieu para el estudio de trayectorias intelectuales de agentes e \\ instituciones
}

\section{Jefferson Teles Martins ${ }^{\mathrm{i}}$}

Resumo: Este artigo busca fornecer algumas reflexões sobre o estudo dos intelectuais e as possibilidades de aproximação metodológica com o tema. A partir de duas experiências de investigação, uma no mestrado e outra no doutorado ${ }^{\text {ii }}$ ligadas ao universo dos intelectuais, o texto busca trazer apontamentos que possam servir aos que se interessam nessa área de estudos. A primeira parte aborda as contribuições teóricas de Pierre Bourdieu para o estudo dos intelectuais associadas ao método prosopográfico e ao estudo de redes; a segunda parte busca fazer uma aproximação metodológica para a definição do grupo a ser investigado na pesquisa sobre intelectuais.

Palavras-chave: Bourdieu. Intelectuais. Prosopografia.

\begin{abstract}
The purpose of this article is to provide some reflections on the study of intellectuals and the possibilities of methodological approach to this theme. From two research experiences, one in the master's degree and the other in the doctorate, the participation in the universe of intellectuals, here seeks to bring indicators that may be useful for those interested in this area of study. In the first part, it deals with Pierre Bourdieu's theoretical contributions to the study of intellectuals associated with the prosopographic method and the study of networks; and in the second, we seek to make a methodological approach to the definition of the group to be investigated in research about intellectuals.
\end{abstract}

Keywords: Bourdieu. Intellectuals. Prosopography.

Resumen: El propósito de este artículo es proporcionar algunas reflexiones sobre el estudio de los intelectuales y las posibilidades de acercamiento metodológico a este tema. A partir de dos experiencias de investigación, una en la maestría y otra en el doctorado, vinculadas al universo de los intelectuales, busca-se aquí traer notas que puedan servir a aquellos que estén interesados en esta área de estudio. La primera parte aborda las contribuciones teóricas de Pierre Bourdieu al estudio de los intelectuales asociados con el método prosopográfico y el estudio de las redes; y en el segundo, se busca hacer un enfoque metodológico a la definición del grupo que se quiera analizar en la investigación sobre intelectuales.

Palabras clave: Bourdieu. Intelectuales. Prosopografia. 


\section{Imigração de ideias e conceitos}

Primeiramente, deve delimitar-se o contexto das duas investigações realizadas que serviram de quadro geral para as reflexões que são aqui trazidas. Ambos os estudos foram feitos sobre o Rio Grande do Sul da primeira metade do século XX. Portanto, as considerações dizem respeito ao meio intelectual de condições específicas daquela época e restringem-se a um espaço periférico, longe dos centros de agentes e instâncias principais do universo intelectual brasileiro. A despeito disso, esse espaço regional - o Rio Grande do Sul - possuía um conjunto de condições que permitia a atuação e o relativo reconhecimento desses intelectuais regionais. Essas condições favoráveis à criação de um espaço de atuação intelectual podem ser assim resumidas: imprensa vigorosa desde meados do século XIX; elevação dos níveis de alfabetização no estado; criação, no final do século XIX, de instituições de ensino superior; existência de livrarias que atuavam como casas publicadoras, com destaque para a Livraria Americana, em Pelotas, e a Livraria do Globo, em Porto Alegre; circulação de almanaques e anuários, que foram importantes na formação mental e divulgação da cultura histórica no estado, especialmente o Anuário do Estado, de Graciano Azambuja, e o Almanaque Estatístico e Literário, de Alfredo Ferreira Rodrigues (que circularam por três décadas).

No final do século XIX, pode-se dizer que o Rio Grande do Sul possuía dois polos de produção e circulação da cultura: Porto Alegre e Pelotas. Aí estavam as principais livrarias, bibliotecas, jornais e onde eram produzidos os almanaques. Com o fim do Império e início da República, Porto Alegre ascende economicamente, ao passo que Pelotas perde a posição de principal polo econômico estadual. Essa mudança se verifica também no incipiente universo de produção cultural. A Livraria do Globo se consolida como a principal do estado e como casa publicadora de escritores regionais, tornando-se uma referência em termos de reconhecimento de escritores e poetas locais. Esse último aspecto adquire relevo quando se pensa em outros espaços regionais distantes do país que não lograram consolidar editoras locais. No Rio Grande do Sul, esse fato propiciou, entre outros fatores, a criação de um espaço interno de circulação dos escritores locais e suas obras e, consequente, visibilidade e reconhecimento adstritos ao meio regional.

Muito resumidamente esse é o quadro dentro do qual se moveram os agentes e as instituições que fizeram parte das investigações realizadas. Portanto, é sobre esse recorte que as reflexões e os apontamentos trazidos neste artigo dizem respeito. Nesse sentido, a primeira consideração é de natureza teórica e pode ser estendida aos dois estudos, embora no primeiro a preocupação tenha sido mais nas condições sociais do universo cultural do Rio Grande do Sul utilizando como fio condutor da investigação e análise a trajetória de um intelectual em particular Jorge Salis Goulart - e, no segundo, a ênfase tenha sido maior na atuação e mobilização de um grupo de intelectuais - membros do Instituto Histórico e Geográfico do Rio Grande do Sul (IHGRGS). Impõe-se a necessidade de se refletir sobre o aporte teórico e conceitual utilizado, suas 
potencialidades e limites.

Os estudos se ampararam, em boa medida, no arcabouço teórico e conceitual produzido por Pierre Bourdieu. Aqui cabem algumas considerações sobre os cuidados necessários em toda imigração de ideias para evitar vários perigos de ingenuidade e simplificação, pois separa as produções culturais do sistema de referências teóricas que as produziu. Impõe-se a necessidade de atualização do horizonte de referência (BOURDIEU, 2006), para evitar a utilização de conceitos e noções que foram criados para resolver os problemas de compreensão e interpretação do mundo social com organizações complexas e altamente diferenciadas, como é o caso da teoria bourdiana, e tentar aplicá-los a um contexto diverso. Este é um cuidado que deve perpassar todo o trabalho que utiliza referências teóricas de outro autor. Mesmo na análise das sociedades que serviram de referência a Bourdieu, é recomendada cautela para fugir de reificações e a uma pretensa pureza ou essencialização dos conceitos. Assim, o propósito, nas investigações, não foi ser intérprete fiel de Bourdieu, mas utilizar sua proposta teórica como inspiração na busca por instrumentos de análise e compreensão do universo social em que se moviam os intelectuais no sul do Brasil, nas primeiras quadras do século XX.

Dessa forma, no contexto analisado, em vez de um campo intelectual relativamente autônomo, foi percebido pela investigação um espaço social de atuação intelectual estreitamente vinculados a outras esferas, especialmente a política. Por outro lado, a relativização dos conceitos e a quebra da rigidez teórica não anularam a eficácia e pertinência da teoria dos campos, especialmente na análise dos recursos sociais dos agentes. Esses recursos ou capitais, a despeito da porosidade de interesses entre diferentes esferas ou espaços de atuação, não são completamente redutíveis ao campo político, conquanto fosse esse um espaço fundamental de interesse e atuação dos agentes. Por isso, a relação dos intelectuais com o espaço de poder é um ponto privilegiado nas investigações dessa natureza, especialmente para descobrir como aqueles agentes lidavam com as limitações e coações impostas dentro da estrutura de relações objetivas da esfera política.

Outra noção importante que se mostrou válida para as duas pesquisas é o conceito de poder simbólico, ou seja, um poder reconhecido definido pelo peso dos diferentes agentes que depende de seu capital simbólico, ou seja, do reconhecimento, institucionalizado ou não, que obtém de um grupo. Segundo a perspectiva do sociólogo francês, as posições dos agentes em um determinado campo dependem do seu volume de capital. A posição e o capital definem o poder de um agente dentro do campo, devendo este poder ser reconhecido pelos demais agentes do campo. Essa ideia é especialmente útil para se pensar a posição de um agente em relação aos demais e para recuperar as suas microestratégias na busca por um espaço no meio no qual querem ser inseridos. Para Bourdieu, o poder simbólico é sempre arbitrário e ilegítimo e se baseia no desconhecimento, por parte dos dominados, dessa arbitrariedade e da aceitação das regras do jogo. Assim, segundo ele, é um poder que necessita ser descoberto - pelo pesquisador - "onde ele se deixa ver menos, onde ele é mais completamente ignorado, portanto, reconhecido: o poder simbólico é com efeito, esse poder 
invisível o qual só pode ser exercido com a cumplicidade daqueles que não querem saber que lhe estão sujeitos ou mesmo que o exercem" (BOURDIEU, 1989, p. 7-8).

A perspectiva relacional que toma os agentes e grupos de agentes em seu caráter de antagonismos e relações de força e recursos também está presente na teoria bourdiana e, por meio dela, o espaço social é visto sobretudo como um espaço de lutas e concorrências entre os agentes na busca pelo monopólio do poder. No caso do espaço social de atuação intelectual, essas lutas referemse à possibilidade de incorporar os recursos intelectuais objetivados. Nas condições históricas em que se movimentavam os intelectuais da década de 1920 no Rio Grande do Sul, o motivo principal das lutas era o reconhecimento na forma de prestígio intelectual. Assim, trabalha-se com a ideia de posições que compõem um “jogo móvel”, no qual os agentes não possuem posições fixas. Os agentes dominantes no campo lutam para preservar suas posições e capitais, enquanto que os dominados lutam para conquistar recursos e melhores posições dentro do campo. Daí, tem-se outra noção importante: a trajetória que, para Bourdieu, é "uma série de posições sucessivamente ocupadas por um mesmo agente (ou um mesmo grupo) num espaço que é ele próprio em devir, estando sujeito a incessantes transformações" (1996, p. 189). Através de tomadas de decisão e de posições os agentes vão construindo suas trajetórias com vistas a obter cada vez mais prestígio e reconhecimento.

Sobre a relação indivíduo/sociedade e as formas de estabelecer esses laços, Pierre Bourdieu, no clássico diálogo com Roger Chartier, publicado sob o título Gente com história, gente sem história, disse entender que a oposição entre sujeito e estrutura, objetividade e subjetividade, indivíduo e sociedade é um falso problema, embora esteja assentado em interesses sociais verdadeiros. Para ele, no entanto, é necessário objetivar os fatos sociais e tratá-los como coisas, ou ainda, estudar os indivíduos "como se não possuíssem subjetividade; estudá-los sem atribuir importância ao que dizem, à sua experiência vivida, a suas experiências mentais, a suas representações" (BOURDIEU; CHARTIER, 2006, p. 91). Pois, para o sociólogo, as representações e os discursos - a verdade subjetiva - dependem do ponto no espaço social em que o indivíduo está situado - a verdade objetiva (idem, ibidem, p. 92). Esses parâmetros são úteis para compreender o "ponto no espaço social" a partir do qual os intelectuais falavam e, assim, entender o sentido de suas falas.

As premissas do pensamento bourdiano se conectam muito bem com alguns métodos de investigação como a prosopografia e o estudo das redes, quando o universo de investigados remete a um grupo de agentes ou a um coletivo membro de uma instituição que agrega intelectuais. Foi esse o caso do segundo estudo que serviu de base para as reflexões apresentadas neste artigo e que teve como objeto de análise o IHGRGS e seus membros. Aquele estudo quis entender as dinâmicas sociais internas à instituição enquanto "corporação intelectual" (de 1920 a 1956), através da abordagem sociológica e do enfoque prosopográfico associado ao estudo das redes de relações e solidariedades intelectuais. Utilizando as ferramentas e as possibilidades da sociologia histórica para o estudo da prática dos agentes daquela instituição, a pesquisa explorou a trajetória do IHGRGS, 
desde sua fundação em 1920, passando pelo momento do auge do seu protagonismo na esfera intelectual sul-rio-grandense até o momento em que se instaurou a crise institucional e de legitimidade, na década de 1950. O recorte cronológico se deu em função do protagonismo da instituição na produção do saber histórico no Rio Grande do Sul, desde seu surgimento até o momento de crise e tentativa de revisão historiográfica que iniciou o processo de questionamento da instituição como produtor legítimo da história regional, que teve como marco inicial a dissensão institucional e historiográfica em torno do caso Sepé Tiaraju, em meados dos anos 1950. Portanto, o estudo visou reinserir os agentes e o grupo de agentes produtores da historiografia do IHGRGS no sistema de relações como uma categoria "particular" de escritores na estrutura do espaço social dos intelectuais sul-rio-grandenses e brasileiros.

É importante salientar que, aqui, a teoria bourdiana não possui sentido teleológico, ou seja, não se considera que os campos se organizam numa escalada progressiva de autonomização e organização. Um campo que inicia o processo de estruturação e diferenciação poderá experimentar um estágio de organização maior em um dado período e, em seguida, sofrer um processo de diminuição dessa organização. Da mesma forma que uma instituição que se lança precocemente na luta pelos trunfos e pelo poder simbólico, atuando desde a organização de um determinado campo e conquistando uma posição central, pode, depois, ser deslocada para uma posição subordinada dentro do espaço que ajudou a organizar. Assim, buscou-se retomar dois processos naquele estudo: 1) a organização do espaço social intelectual rio-grandense; 2) o processo de valorização e desvalorização social do IHGRGS ao longo do tempo, para dar resposta a duas questões: a) que posição a instituição assumiu em relação aos grupos estabelecidos (elites e campo do poder)? b) existiu uma relação entre as diferenças ou clivagens internas e as distintas origens e vias de acesso de seus membros ao Instituto e ao status de intelectual?

Outra questão enfrentada no trato com grupos ou corporações é a visão de uma elite intelectual "unificada", visão aliás que aqueles intelectuais tinham interesse em propagar porque dizia respeito à própria imagem e identidade de grupo que visavam afirmar. E aí se reconhece a eficácia do poder simbólico que se dá, segundo Bourdieu, quando se mascaram (ou dissimulam) as hierarquias e as lutas dentro de um determinado campo.

Um dos pontos que merece bastante atenção e parece útil para o desvelamento das posições de um indivíduo em um determinado espaço social é a investigação em torno dos atributos sociais e simbólicos (individuais e coletivos) para descobrir o ponto no espaço social a partir do qual estes agentes intelectuais se moviam em relação (1) uns aos outros, (2) a outros intelectuais do "centro" do país, e (3) em relação a agentes de outros espaços, especialmente, o político. Os atributos sociais objetivados só fazem sentido quando tomados em seu aspecto relacional, porque assim revelam a hierarquia das posições dentro de um dado espaço, e sua lógica de funcionamento. Equivalem a trunfos numa correlação de forças que dão sentido e explicitam as estratégias dos agentes, suas tomadas de posição, seus enfrentamentos e a formação das suas redes de solidariedade. Portanto, 
segundo a perspectiva adotada, o sentido do discurso historiográfico dos agentes é compreendido não apenas segundo a lógica interna, mas a partir da posição na estrutura objetiva de relações em que estão situados, pois o jogo entre fala e posição reproduz um campo de lutas simbólicas que ocorrem no âmbito das práticas sociais e que responde a interesses sociais precisos (políticos, intelectuais, editoriais, culturais). Assim, os discursos podem revelar mais do que a oposição (ou tensão) e integração (ou acomodação) de ideias (políticas) e mostrar os alinhamentos e as disputas internas do grupo estudado. Tratar os discursos como fato social significa atentar menos para os seus argumentos internos e mais para as condições sociais da sua produção, assim como para os constrangimentos sociais, políticos e intelectuais que envolviam o tema e os seus produtores.

Como resultado desta abordagem, pode-se visualizar mais claramente as problemáticas legítimas da hierarquia na agenda intelectual e dos constrangimentos disciplinares decorrentes - em uma palavra, a "estrutura" do espaço social. Portanto, a sociologia da produção historiográfica, fundamentada no universo conceitual proposto sobretudo por Pierre Bourdieu, tem enfoque na análise das relações que situam, dentro da esfera intelectual, as diferentes posições, as diferentes estratégias e a construção social da agenda intelectual, considerando o espaço dos produtores com vistas à apreensão das condições e possibilidades de diferenciação de um espaço.

A prosopografia como meio de investigação das características sociais dos membros de uma agremiação intelectual, seus atributos e capitais sociais, é útil para objetivar os mecanismos de reprodução e recrutamento social e as suas estratégias de carreira. Naquilo que diz respeito ao tipo de investimento inicial de carreira, a prosopografia não fornece diretamente as respostas, mas ajuda a reunir elementos para enfrentar alguns questionamentos, tais como: houve alteração no padrão de investimento inicial de carreira intelectual (obra de estreia) ao longo do período estudado para o conjunto de historiadores contemplado no presente estudo? Se houve, qual foi a tendência desse investimento? Quais os padrões ou as escalas de reconhecimento intelectual ao longo do período e suas alterações, se houveram? A prosopografia, por ser um instrumento de análise coletiva, fornece maiores subsídios ou indícios que permitem adensar as respostas para estas perguntas do que se se utilizasse apenas a análise de trajetórias individuais como fio condutor.

Em outro sentido, a perspectiva relacional de Bourdieu se alinha bem com a reconstituição das redes ${ }^{\mathrm{iii}}$ de relações dos agentes, a qual permite a melhor compreensão dos diversos vínculos que fazem parte do jogo de alianças da elite intelectual. Levando-se em conta que os agentes ocupam diferentes posições no espaço social, o estudo das redes daqueles intelectuais é capaz de revelar muito sobre a estrutura e a hierarquia do meio institucional, especialmente quando se escolhem momentos de crise ou polêmicas, sempre com um olhar atento para as alianças (que podem ser apenas táticas ou mais duradouras) em torno de protagonistas e antagonistas. A reconstituição de redes pode ser desenvolvida em dois níveis, pessoal e institucional. 


\section{Definição do grupo e "grupo na rua"}

A segunda consideração deste artigo é de natureza metodológica e diz respeito à escolha do grupo de agentes que serão objeto da investigação.

A definição de um conceito de intelectual não é tarefa fácil. A questão da imprecisão deste conceito já foi destacada por diversos autores. A respeito desse tema, Jean François Sirinelli afirma: "com freqüência se destacaram o caráter polissêmico da noção de intelectual, o aspecto polimorfo do meio dos intelectuais e a imprecisão daí decorrentes para se estabelecer critérios de definição da palavra" (SIRINELLI, 1996, p. 242). Também neste sentido o historiador Roger Chartier comenta a indefinição do conceito: "às certezas lexicais das outras histórias, a história intelectual opõe uma dupla incerteza do vocabulário. Cada historiografia nacional possui suas próprias designações, e em cada uma delas diferentes noções, mal distintas umas das outras, entram em competição" (CHARTIER, 1993, p. 373). Por essa razão, a noção de intelectual está estritamente ligada ao contexto das práticas intelectuais que se pretende investigar e revela-se a partir da ideia de um espaço de sociabilidade, inserido na noção de campo de produção cultural. Este espaço é onde as obras são elaboradas e onde se tramam as carreiras. Mais do que tentar definir as fronteiras fechadas do campo intelectual e procurar dizer o que é ser intelectual, um objetivo relevante é tentar compreender como o espaço social dos intelectuais funciona e se organiza e perceber quem são as pessoas que nele circulam, quem dá as cartas do jogo, quem define os critérios de uma problemática legítima e a agenda intelectual (em sentido mais amplo) ou institucional (em sentido restrito). O conceito de intelectual pode ser tomado em seus usos pelos agentes, pois assim o estudo tende a se remeter às práticas socialmente enraizadas daqueles agentes.

A história dos intelectuais "é um campo aberto, situado no cruzamento das histórias política, social e cultural" (SIRINELLI, 1996, p. 232). Jean François Sirinelli sugere que o meio intelectual deve ser visto como um meio polimorfo e entende que sua definição deve possuir uma geometria variável, mas baseada em invariantes, resultando em duas acepções: uma ampla e sociológica, englobando os criadores e mediadores culturais, e outra estreita, baseada na noção de engajamento. A primeira compreende os estudos exaustivos e extensivos. A segunda inclui os estudos mais focados. Mas Sirinelli reconhece que uma não é autônoma da outra (SIRINELLI, 1996).

As questões que se apresentam ao pesquisador no processo de definição ou escolha do grupo de agentes que será objeto de sua pesquisa, notadamente no estudo de biografias coletivas de intelectuais, o confrontam com o problema do "efeito de teoria" ou a "ilusão intelectualista", ou seja, quando um grupo que existe apenas no papel é confundido com um grupo real. Para enfrentar o problema, cabem duas considerações: a) sobre o momento de definir o recorte da pesquisa e os critérios usados para definir o grupo (a própria definição de intelectuais, os critérios levados em conta - relacionais ou posicionais); b) sobre o viés da aproximação (e o distanciamento) do grupo a 
ser estudado, utilizando as noções de mobilização e tomada de consciência, como instrumento de ajuste do foco da análise para escapar ao efeito de teoria. É o que se faz a seguir.

O historiador dos intelectuais, num primeiro momento, quando no processo de definição e delimitação do seu objeto de pesquisa, parece ver confrontarem-se duas possibilidades de abordagens entre as quais deveria optar: uma que privilegia a análise externa ou objetiva, e outra que valoriza a análise interna ou subjetiva. A primeira seria o monopólio do sociólogo ou do historiador, e a segunda obedeceria a uma divisão tradicional do trabalho, reserva dos intelectuais da literatura (críticos, filósofos e historiadores da arte e da literatura) (CHARLE, 2006). Essa dicotomia encerra apenas uma cilada inicial ao se fazerem estudos sobre intelectuais. Optar por uma ou outra solução metodológica corresponde a cair em uma armadilha de reducionismo. Se, por um lado, o trabalho ou a produção intelectual não pode ser completamente explicada pela análise sociológica, por outro, esta análise não pode ser negligenciada sob pena de cair na ilusão de que as ideias "andam sozinhas pelas ruas". As ideias partem da mente de homens de carne e osso, com engajamentos explícitos ou não, interesses declarados ou ocultos, que, por sua vez, se relacionam com outros homens com interesses e engajamentos variados, dentro de contextos sociais amplos ou específicos em múltiplas instâncias. Portanto, a análise sociológica é tão importante quanto entender as ideias, ideologias e engajamentos desses indivíduos.

O estudo sobre intelectuais confronta o pesquisador com a difícil questão teórica já mencionada da definição do termo e, derivadamente, com o problema metodológico da escolha ou definição do grupo de intelectuais a ser estudado. Quem e o que é ser intelectual? E segundo que critérios se processa o recorte metodológico que define quem faz parte ou não do grupo ou da população a ser estudada (numa biografia coletiva)? Uma opção é o estudo dos intelectuais a partir do sistema de relações constitutivas da classe de fatos de que forma parte sociologicamente, em outras palavras, partindo da problemática sociológica das relações sociais e do ponto no espaço social em que se eles encontram. Tal perspectiva leva em conta as diferentes formas de reconhecimento que um intelectual recebe dos seus pares, as sociabilidades e as redes de que fazem parte, seus móveis e instrumentos de luta, assim como sua estratificação nas escalas de reconhecimento. Esse tipo de abordagem tem a vantagem de reconhecer que os intelectuais existem como fato sociológico e, também, de levar em conta as suas relações de sentido, suas imagens recíprocas, ou ainda, "sua capacidade em impor uma imagem de si mesmos aos outros" (CHARLE, 2006, p. 44). Isto significa compreender os intelectuais como grupo socialmente - e não cientificamente - construído. O estudo das elites, em geral, se caracteriza pelo fato de elas terem a capacidade de "impor sua visão de mundo" ao universo social envolvente. E, dentro das elites, talvez os intelectuais sejam o grupo que melhor consegue cumprir este papel. No entanto, esse tipo de abordagem recebeu críticas que foram assinaladas primeiramente por Lawrence Stone (como Cristophe Charle chama a atenção) às abordagens do método prosopográfico ou biográfico coletivo, que, para definir os grupos a serem estudados, utilizam as propriedades relacionais do próprio grupo 
(e suas relações de sentido), pois isso levaria a "uma visão elitista, cínica e conformista dos grupos dirigentes e de suas relações com a sociedade que os envolve" (CHARLE, 2006, p. 45). Entretanto, existe grande diferença entre, de um lado, tomar ingenuamente (ou cinicamente) o discurso ou a visão que os agentes tinham de si mesmos como verdadeiros, pois isto seria apenas legitimar a visão e a voz daqueles agentes, e, de outro, utilizar esses mesmos elementos para mapear as suas disposições e propriedades relacionais, a fim de situá-los no espaço social. O perigo de criar um efeito de teoria é real e inerente a qualquer pesquisa que trabalha com grupos ou classes de indivíduos, mas o sucesso do trabalho depende do cuidado do historiador em não confundir, nos termos colocados por Bourdieu (2001), a coisa da lógica com a lógica das coisas. Assim, tomar as imagens recíprocas evocadas pelos intelectuais como ponto de partida para a definição de um grupo a ser estudado e tomar essas evocações como verdadeiras são coisas distintas. Uma vez definido o grupo, cabe ao historiador conduzir a pesquisa de maneira que não caia nas ciladas do discurso, pelo cotejamento com outras fontes, não apenas as produzidas pelos intelectuais (CHARLE, 2006).

Outra forma de estabelecer uma população-alvo em estudos de elites em geral, e que poderia ser utilizado também para o caso dos intelectuais, é o critério posicional. Esse critério consiste em utilizar listas de membros de instituições públicas ou privadas que agregam agentes da elite. No caso de intelectuais, estas instituições podem ser academias literárias, institutos históricos, ou mesmo cargos públicos ligados ao universo cultural. Esta opção metodológica parece ter a vantagem de livrar o pesquisador do julgamento arbitrário de quem entra ou não no grupo, mas a escolha do grupo ou da instituição-alvo já envolve a priori um processo arbitrário. Posteriormente, o investigador que opta pelo critério posicional irá se deparar com as mesmas questões metodológicas daquele que escolheu o critério relacional, pois nem todos os agentes dentro do grupo selecionado receberão a mesma atenção, já que se situam em pontos distintos do espaço social estudado. O peso de um agente dentro de um espaço social depende do seu volume de capital, de sua posição dentro das redes relacionais daquele espaço. Trata-se, neste caso, apenas de um critério de recorte. O estudo em si comportará as mesmas problemáticas do reconhecimento, das escalas de prestígio, as lutas, enfim, a natureza do campo intelectual. Quando se opta pelo critério posicional é, talvez, mais fácil justificar a escolha dos nomes, pois eles fazem parte da lista. No entanto, no decorrer da pesquisa é necessário fugir à visão reificada de um grupo artificial baseado unicamente na nominata de uma instituição. Isso pode ser feito elegendo-se os critérios relacionais como forma de recuperar as trajetórias individuais e coletivas.

Outra problemática suscitada pelo estudo de intelectuais (e não apenas destes) é o processo da transição que sofre um grupo de indivíduos em condições de existência "homogêneas" - que permite práticas semelhantes, pela posse de atributos sociais comuns, as mesmas disposições, um conjunto de competências intelectuais compartilhados - para que se torne um grupo que se reúne e se organiza para uma luta comum. Na verdade, esta preocupação não envolve mais a definição do grupo e, sim, um problema dentro da investigação que, de certa forma, justifica a escolha do grupo. 
Em suma, trata-se de compreender quando um grupo "no papel" se torna um grupo "na rua" (BOURDIEU, 2001). Implica a dupla ruptura, com a ilusão intelectualista que confunde o grupo objetivo com o grupo mobilizado, e com a falsa ideia de que o primeiro se transforma automaticamente no segundo.

A referência clássica para se pensar esta questão é a análise que Charle (2003) fez sobre o Nascimento dos intelectuais contemporâneos (1860-1898). Segundo o historiador francês, esse é um processo amplo que recobre pelo menos a segunda metade do século XIX. Ao analisar este processo, Charle faz evocação do caso Dreyfus, ocorrido no final do século XIX, como um dos momentos de inflexão da história dos intelectuais na França. Alfred Dreyfus era capitão do exército francês, judeu, que foi acusado de espionagem política. O caso de grande repercussão dividiu a opinião pública e levou a elite intelectual francesa a tomadas de posição que se polarizaram entre dreyfusardes (progressistas, à esquerda) e antidreyfusardes (conservadores, à direita). O termo "intelectual", então, foi usado pela primeira vez pelos antidreyfusardes para designar pejorativamente os seus antagonistas. A importância deste episódio para a história dos intelectuais assenta-se em dois pontos: primeiro, marca alguns elementos-chave da atuação pública dos intelectuais nos moldes contemporâneos, ou seja, como agentes que intervêm nos debates públicos da cidade; e, segundo, revela a capacidade de organização e clivagens dos intelectuais em torno de uma luta comum. Esta mobilização coletiva expressa o grau de tomada de consciência dos intelectuais franceses.

A partir destes pressupostos, é possível dizer que entender o processo de tomada de consciência de um grupo é tentar compreender todo o processo de mobilização para que o grupo organizado venha a existir, em outras palavras, a passagem do grupo objetivo "no papel" para o grupo mobilizado "na rua". Portanto, a tomada de consciência de um grupo pressupõe a existência de outros fatores simultâneos, como uma crescente identificação de seus membros, que se veem, ao mesmo tempo, como iguais e diferentes, pois os intelectuais de forma geral "só podem ser considerados como idênticos a partir da afirmação de suas diferenças" (CHARLE, 2003, p. 145).

\section{Considerações finais}

Por fim, convém salientar que existem outras abordagens e métodos que se mostram bastante válidos no estudo dos intelectuais. Não se trata, portanto, de defender a superioridade de uma abordagem sobre as demais. Porém, uma abordagem de inspiração mais sociológica, enfocando as lutas, as solidariedades, hierarquias e as distintas correlações de forças com agentes de outros espaços sociais, pode revelar muito das estruturas elementares do espaço social dos intelectuais e as posições dos agentes. Com relação ao estudo prosopográfico, é preciso reconhecer os limites deste método, especialmente quando se trata de um conjunto que, ao mesmo tempo, não é grande e cujas informações são desiguais e rarefeitas.

Complementarmente, a perspectiva relacional aliada ao estudo das redes lança luz não só 
sobre o jogo de alianças e concorrências entre intelectuais e com agentes de outras esferas, mas também sobre as práticas que definem o que é ser intelectual e como se mobilizam, especialmente em contextos de fraca institucionalização.

\section{Referências}

BERTRAND, Michel. De la familia a la red de sociabilidad. Revista Mexicana de Sociología, México, v. 61, n. 2, 1999, p. 107-135.

BOURDIEU, Pierre. A gênese dos conceitos de habitus e de campo. In: O poder simbólico. Rio de Janeiro: Difel, 1989.

BOURDIEU, Pierre. As regras da arte. São Paulo: Companhia das Letras, 1996.

BOURDIEU, Pierre. Coisas ditas. São Paulo: Brasiliense, 2001.

BOURDIEU, Pierre. Campo del poder, campo intelectual y habitus de clase. Buenos Aires: Eudeba, 2006.

BOUDIEU, P; CHARTIER, R. Gente com história, gente sem história. Diálogo entre Pierre Bourdieu e Roger Chartier. História Unisinos. São Leopoldo, Unisinos, v. 10, n. 1, 2006, p. 90-98.

CHARLE, Christophe. Nascimento dos intelectuais contemporâneos (1860-1898). História da Educação, ASPHE/FAE/UFPel, Pelotas, n. 14, 2003, p. 141-156.

CHARLE, Christophe. A prosopografia ou biografia coletiva: balanço e perspectivas. In: HEINZ, Flavio (org.). Por outra história das elites. Rio de Janeiro: FGV, 2006.

CHARTIER, Roger. Intelectual. In: BURGUIÈRE, André. Dicionário das Ciências Históricas. Rio de Janeiro: Imago, 1993.

MARTINS, J. T. O pensamento histórico e social de Jorge Salis Goulart: uma incursão pelo 'campo ' intelectual rio-grandense na década de 1920. Dissertação de mestrado. PUCRS, 2011.

MARTINS, J. T. O IHGRGS e o espaço social dos intelectuais: trajetória institucional e estudo das redes de solidariedades (e conflitos) entre intelectuais $(1920$ - 1956). Tese de doutorado. PUCRS, 2015.

SIRINELLI, Jean-François. Os intelectuais. In: RÉMOND, René. Por uma história política. Rio de Janeiro: Ed. UFRJ/FGV, 1996.

Submetido em: 21/08/2019

Aprovado em: 04/10/2019

Publicado: 15/12/2019

\section{Notas}

\footnotetext{
${ }^{\text {i }}$ Doutor em história pela Pontifícia Universidade Católica do Rio Grande do Sul (PUCRS). Membro efetivo do Instituto Histórico e Geográfico do Rio Grande do Sul (IHGRGS).E-mail: jeffteles@gmail.com
} 
ii No mestrado (cf. MARTINS, 2011), investiguei a trajetória de Jorge Salis Goulart, escritor, historiador e jornalista sul-rio-grandense. No doutorado (CF. MARTINS, 2015), pesquisei a trajetória do IHGRGS.

iii Estruturas em constante adaptação e dinamismo, que apontam para a complexidade do social, formadas por laços e contatos entre indivíduos em constante relação por meio de intercâmbios e trocas de bens materiais e simbólicos (BERTRAND, 1999). 